\title{
Recomendação de Aplicativos Educacionais Mediada por Interfaces Conversacionais
}

\author{
Cristina Paludo Santos, Laiana Andrade Roland, Denilson Rodrigues da Silva
}

Universidade Regional Integrada do Alto Uruguai e das Missões (URI) 98.802-470 - Santo Ângelo - RS - Brasil

paludoesan.uri.br, laianarolandehotmail.com, deniro@san.uri.br

\begin{abstract}
This paper describes efforts aimed at encouraging learning activities using a conversational agent named Dory. Chatbot aims to recommend educational applications that can be used as a complement to student training. Elementary school teachers participated in the process of ideation, mainly in the activities that involved the evaluation / selection of the applications to be recommended. A case study was carried out with the participation of 6th and 7th grade students. A qualitative analysis was carried out that evidenced the potential applicability of chatbot for this context.
\end{abstract}

Resumo. Este artigo descreve os esforços direcionados para ensejar atividades de aprendizagem utilizando um agente conversacional nomeado Dory. $O$ chatbot tem como foco a recomendação de aplicativos educacionais relacionados às matérias escolares do currículo base visando complementar a formação dos estudantes. Professores do ensino fundamental participaram do processo de ideação, principalmente nas atividades que envolveram a avaliação/seleção dos aplicativos a serem recomendados. Um estudo de caso foi realizado com a participação de alunos do $6^{\circ}$ e $7^{\circ}$ anos. A análise qualitativa realizada evidenciou o potencial de aplicabilidade de chatbot no contexto em questão.

\section{Introdução}

Ao longo dos últimos anos foi-se matizando novas abordagens pedagógicas permeadas pela inserção das Tecnologias de Comunicação e Informação (TICs) a fim de favorecer e potencializar a complementação dos métodos tradicionais de ensino, gerando formas alternativas e motivadoras de produção e socialização de conhecimentos e informações (Lopes, 2018). Dentre as diversas pesquisas que emergem a partir da relação entre a computação e a educação destaca-se, neste trabalho, aquelas em torno do uso de agentes conversacionais, também conhecidos como chatterbots ou chatbots.

Consoante aos novos paradigmas da educação, chatbots têm sido empregados com os mais variados propósitos. Paschoal (2017) propôs o Ubibot - um chatbot integrado ao ambiente Moodle para auxiliar estudantes no aprendizado de Engenharia de Software. Morais (2017) apresenta Donuts - um chatbot como instrumento facilitador do processo de ensino-aprendizagem na disciplina de Construção de Algoritmos. Raab et al. (2015) apresenta uma abordagem em que o chatbot comporta-se como um gerador de dicas sobre erros cometidos por estudantes na construção de um programa de computador, auxiliando os alunos na resolução de exercícios. Além destes, vários outros 
trabalhos fazem uso de chatbot a nível educacional, especialmente em sistemas de aprendizagem de Educação a Distância e online (e-learning), chegando também a ambientes imersivos 3D (Sgobbi et al., 2017)

Com o intuito de contribuir para este cenário em que o uso das TICs apresenta-se como um instrumento potencializador para o processo de aprendizagem e, considerando os resultados positivos e promissores apontados por diversos autores quanto ao uso de chatbots na educação (Bii, 2013; Benotti et al., 2014), este artigo apresenta Dory - um agente conversacional ou chatbot que tem como propósito a recomendação de aplicativos/softwares educacionais relacionados às matérias escolares do currículo base visando complementar a formação dos estudantes.

Uma descrição mais detalhada dos aspectos técnico-pedagógicos considerados na concepção do chatbot Dory é apresentada nas seções subsequentes. A Seção 2 descreve os procedimentos metodológicos adotados para sua concepção. A Seção 3 apresenta as principais características do chatbot. A Seção 4 apresenta os resultados obtidos a partir da disponibilização do chatbot para alunos do $6^{\circ}$ e $7^{\circ}$ ano do ensino fundamental. Por fim, a Seção 5 apresenta as considerações finais e direcionamentos futuros.

\section{Procedimentos Metodológicos}

O desenvolvimento de Dory surge como o estabelecimento de estratégias que possam servir de apoio ao professor para dinamizar suas práticas de ensino com o uso das TICs e, também, atuar como instigador dos tópicos de estudos, resultando em um maior engajamento dos estudantes. A metodologia de design adotada para a concepção do chatbot Dory baseia-se em preceitos do Design Experiencial (Buccini, 2008) na medida em que se busca prover uma solução que gera novos significados e que estimulam os diversos aspectos, sejam cognitivos, emocionais e sensoriais envolvidos na experiência humana. Para tanto, utilizou-se os pressupostos advindos das metodologias UX (User Experience) para estruturação do processo de design do chatbot Dory. O processo envolve as fases de Inspiração, Ideação, Prototipação e Avaliação, sendo que cada fase é dependente daquela que a precede, de modo que as decisões na fase de inspiração têm reflexos em todas as demais fases.

A fase de ideação compreende a definição das principais características do chatbot, tais como, o seu propósito, o público a ser beneficiado, sua personalidade e suas tarefas conversacionais. O delineamento das tarefas conversacionais, bem como a definição dos aplicativos educacionais que seriam recomendados foram atividades realizadas juntamente com 7 professores de uma escola pública que atuam nas disciplinas de Português, Matemática, História, Geografia, Ciências, Espanhol e Inglês. Nesta fase também é realizada a modelagem do fluxo de interações, considerada uma das atividades mais importantes no processo de criação do chatbot visto que organiza os elementos que integram a experiência do usuário durante a interação.

Para implementação do chatbot utilizou-se a ferramenta Manychat na sua versão gratuita com uma interface baseada no Facebook Messenger. A metodologia adotada contempla também uma fase de avaliação sobre a experiência do usuário buscando obter feedbacks que subsidiem aprimoramentos para as novas versões, de modo que o processo seja cíclico a cada nova atualização do chatbot Dory. 


\section{Principais características do Chatbot Dory}

Em sua primeira versão o chatbot, nomeado Dory, destina-se aos estudantes do $6^{\circ}$ e $7^{\circ}$ ano e comporta-se como um guia fazendo recomendações de aplicativos que possam ser utilizados como recursos de aprendizagem extraclasse. Dory tem uma personalidade amigável, intelectual e criativa, utiliza uma linguagem não formal, mas adequada para o contexto e público a qual se destina.

Dory caracteriza-se como um sistema de interface conversacional baseado em regras, ou seja, a interação entre o agente conversacional e o usuário ocorre através de seleção predefinida de escolhas que o usuário pode realizar para o dado contexto. Através desse controle de ações o agente pode manter um histórico da navegação e, a partir disso, é possível incrementar a base de conhecimento do bot a fim de aprimorar a experiência do usuário em suas próximas interações, recomendando novos aplicativos nas áreas de maior interesse do aluno.

Seu fluxo de ações inicia com as boas-vindas ao aluno e apresentação do propósito do bot. Logo após Dory indaga o usuário sobre o ano escolar que está cursando e a disciplina de seu interesse. De acordo com as informações fornecidas pelo usuário, Dory recomendará uma lista de aplicativos que possam interessar ao usuário. O usuário tem a opção de baixar o aplicativo ou receber mais informações sobre o mesmo, tais como uma descrição sobre suas finalidades, plataforma para a qual está disponível, repositório onde pode ser obtido e o tipo de acesso (gratuito ou pago). A Figura 1 apresenta algumas interfaces conversacionais do bot.

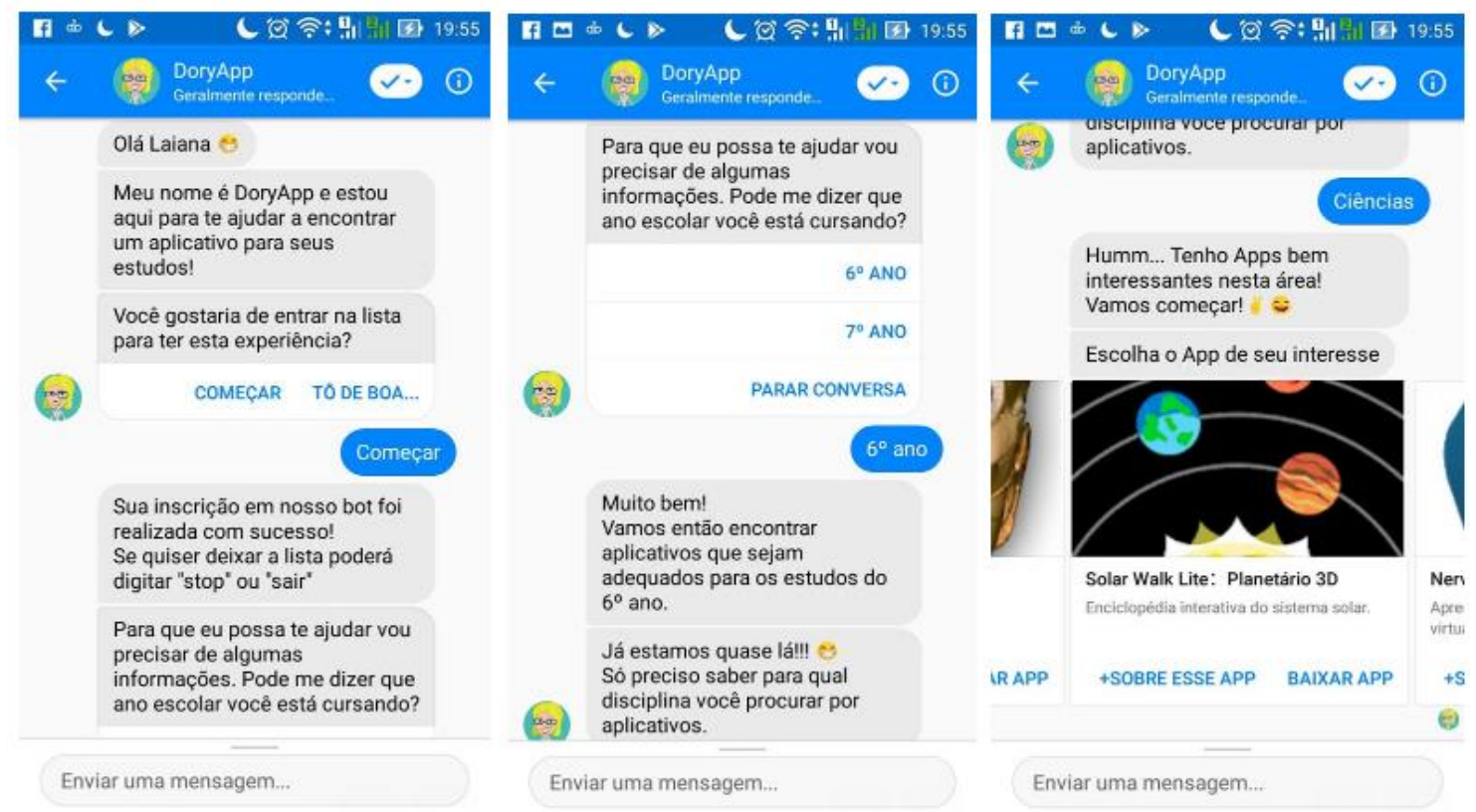

Figura 1. Interfaces de Interação do chatbot Dory

Nesta implementação inicial do chatbot são recomendados 44 aplicativos de acordo com a base de conteúdos de $6^{\circ}$ e $7^{\circ}$ anos vinculados às disciplinas de Português, 
VIII Congresso Brasileiro de Informática na Educação (CBIE 2019)

Anais do XXV Workshop de Informática na Escola (WIE 2019)

Matemática, História, Geografia, Ciências, Espanhol e Inglês. Os aplicativos recomendados estão disponíveis em repositórios diversos disponíveis na Web.

\section{Processo Avaliativo e Resultados Obtidos}

Considerando que a participação ativa dos estudantes no processo avaliativo é extremamente importante, o chatbot desenvolvido foi disponibilizado para alunos do $6^{\circ}$ e $7^{\circ}$ ano do ensino fundamental. Tal processo permitiu analisar a reação dos alunos ao interagirem com o chatbot verificando se este é motivador para ser usado como material de aprendizagem; proporciona uma boa experiência de uso e gera uma percepção de utilidade educacional. Os dados foram analisados qualitativamente através das técnicas de inspeção e questionário.

Por meio da técnica de inspeção verificaram-se aspectos como: (a) o tempo de permanência do usuário na interação com o chatbot; (b) a quantidade de interações que o usuário precisa realizar para ter o que deseja no chatbot e, (c) o envolvimento do usuário com o chatbot. Já, o questionário, composto por 9 questões fechadas e disponibilizado para os usuários por meio de broadcast no próprio bot, serviu para avaliar se o agente conversacional atende as necessidades dos usuários.

Participaram do processo avaliativo 45 alunos, sendo 25 deles do $6^{\circ}$ ano e 20 do $7^{\circ}$ ano. Os dados coletados da interação demonstraram que $94 \%$ sentiram-se satisfeitos ao utilizar o bot, atribuindo nota de 7 a 10, 6\% apontaram sua satisfação como regular, atribuindo nota de 4-6. Alguns alunos expuseram verbalmente que gostariam de fazer perguntas ao bot e não apenas selecionar as opções

Foi unanime a facilidade de entendimento e interação com o bot. Além disso, todos consideraram a linguagem clara e o objetivo do bot muito interessante. Ao serem indagados se encontraram aplicativos interessantes para seus estudos, 97\% apontaram "Sim" como resposta. Ao analisar o tempo permanência na lista, verificou-se que todos optaram em continuar como membro da lista após a atividade realizada, sendo que $71 \%$ continuam envolvidos, ou seja, interagem com frequência com o bot e $29 \%$ estão ativos, mas não interagiram em outros momentos além daquele instigado pela professora.

Quanto ao número de interações realizadas para alcançar um objetivo, $63 \%$ utilizaram de 1 a 5 mensagens, $29 \%$ de 6 a 10 e apenas $8 \%$ necessitaram de mais de 10 interações até encontrar o que procuravam. Estes dados servem como subsídios para futuras reformulações no fluxo de interação de modo que o número de interação seja o menor possível para que os usuários consigam realizar sua tarefa de forma mais rápida.

\section{Considerações Finais e Direcionamentos Futuros}

Este artigo apresentou uma proposta para ensejar atividades de aprendizagem utilizando um agente conversacional nomeado Dory, com o objetivo de corroborar com as novas demandas do processo de ensinar e aprender, tornando a aprendizagem mais atrativa, criativa e social.

As observações realizadas e os resultados obtidos apontaram a necessidade de revisão de certos aspectos interacionais de modo a ampliar a qualidade de experiência do usuário. Assim, algumas das discussões que deverão permear as decisões de ampliação do projeto incluem: (a) permitir que em algumas partes do fluxo a interação ocorra em 
VIII Congresso Brasileiro de Informática na Educação (CBIE 2019)

Anais do XXV Workshop de Informática na Escola (WIE 2019)

linguagem natural; (b) ampliar o escopo considerando aplicativos que abordem conteúdos estudados nos demais anos escolares e, (c) incluir formas de coletar a opinião dos estudantes a respeito de cada um dos aplicativos utilizados. Além disso, o chatbot deverá ser constantemente monitorado para que sejam analisados, por exemplo, quais são os aplicativos mais acessados e aqueles que os alunos não demonstram interesse. Tais resultados impulsionam e direcionam ações no sentido de ampliar as potencialidades do chatbot Dory.

Por fim, os esforços foram conduzidos no sentido de agregar mais um mecanismo que possa colaborar positivamente no processo de aprendizagem. Buscou-se auxiliar o aluno em sua jornada focada no aprendizado por meio da agregação de uma ferramenta moderna, interessante e com grande potencialidade para o seu auxílio.

\section{Referências Bibliográficas}

Benotti, L.; Martinez, M.C.; Schapachnik, F. Engaging High School Students Using Chatbots. ITICSE, Sweden, 2014.

Bii, P. Chatbot technology: A possible means of unlocking student potential to learn how to learn. Educational Research, v.4, International Research Journals, p. 218-221, 2013.

Buccini, M. B. P. R. Introdução ao Design Experiencial. 1. ed. Recife: Edição do Autor, 2008.

Lopes, Patrícia SM et al. A survey of recent developments in management cognitive neuroscience and machine learning in educational environment. In: 13th Iberian Conference on Information Systems and Technologies (CISTI). IEEE, 2018.

Morais, Ceres G.B. et al. Donuts: um bot como instrumento facilitador do processo de ensino-aprendizagem na disciplina "Construção de Algoritmos". Revista Eletrônica Argentina-Brasil de Tecnologias da Informação e da Comunicação, [S.1.], v. 1, n. 7, ago. 2017

Paschoal, Leo Natan; CHICON, Patricia M. Mozzaquatro; FALKEMBACH, Gilse Antoninha Morgental. Concepção, Implementação e Avaliação de um Agente Conversacional com Suporte à Aprendizagem Ubíqua. RENOTE, v. 15, n. 1, 2017.

Raab, A. L. A., Jesus, E. A., Hodecker, A., Pelz, F. Avaliação do feedback gerado por um Corretor Automático de Algoritmos. In. Simpósio Brasileiro de Informática na Educação (SBIE), 2015, Maceió. Anais do SBIE 2015. p. 358-366

Sgobbi, F.; et al., "Mundo virtual 3D e Internet das Coisas para motivar mudança de comportamento saudável". Revista Iberoamericana de Educación en Tecnología y Tecnología en Educación. №19, 2017, pp 7-15. 